\title{
Suicide in the Islamic Republic of Iran: an integrated analysis from 1981 to 2007
}

H.R. Ghafarian Shirazi, ${ }^{1,2}$ M. Hosseini, ${ }^{2}$ M. Zoladl, ${ }^{1}$ M. Malekzadeh, ${ }^{1}$ M. Momeninejad, ${ }^{1}$ K. Noorian ${ }^{7}$ and M.A. Mansorian ${ }^{7}$

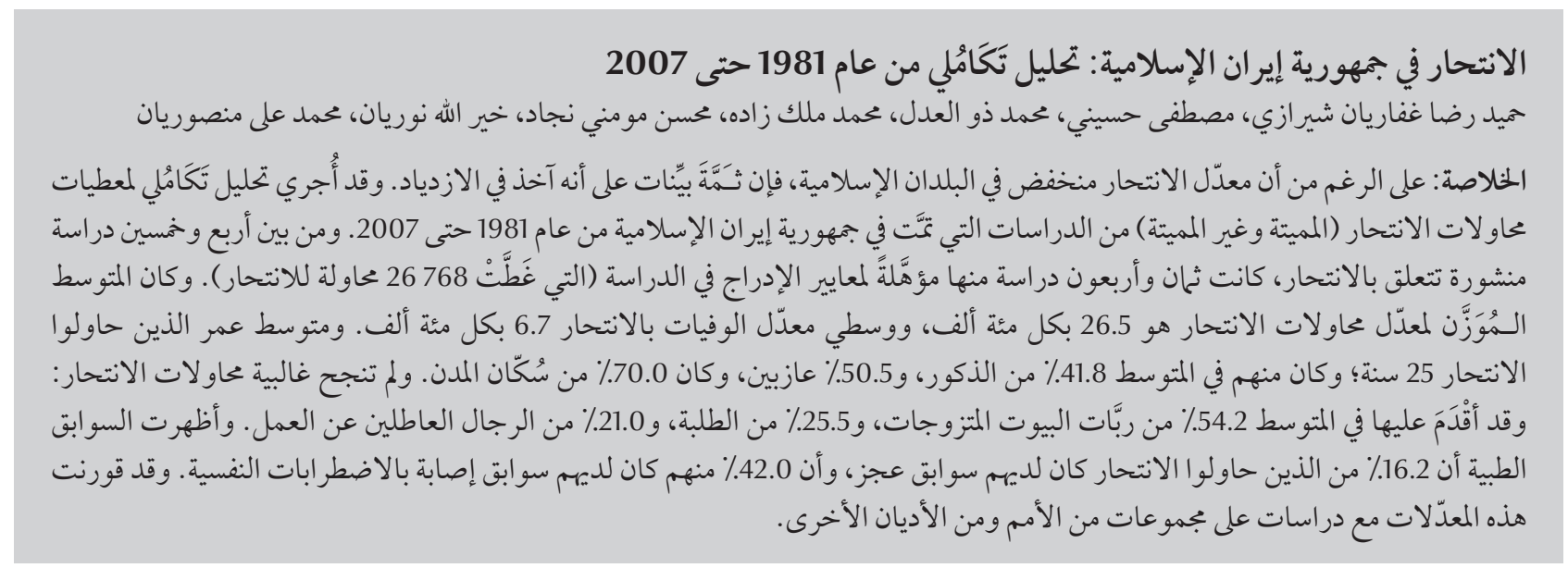

ABSTRACT Although the rate of suicide is low in Muslim countries, there is evidence that it is increasing. An integrated analysis was made of data on suicide attempts (nonfatal and fatal) from studies carried out in the Islamic Republic of Iran from 1981 to 2007. Of 54 published studies concerning suicide, 48 (covering 26768 cases of attempted suicide) satisfied the inclusion criteria. The weighted mean rate of suicide attempts was 26.5 per 100000 and the average rate of death by suicide was 6.7 per 100000 . The mean age of suicide attempters was 25 years; on average $41.8 \%$ were male, $50.5 \%$ single and $70.0 \%$ from urban areas. Most suicide attempters were not working: $54.2 \%$ on average were housewives, $24.5 \%$ students and $21.0 \%$ unemployed men. Medical history showed that $16.2 \%$ of suicide attempters had a history of disability and $42.0 \%$ had a history of psychological disorders. The rates were compared with studies from other nations/religious groups.

\section{Suicides en République islamique d'Iran : une analyse intégrée de 1981 à 2007}

RÉSUMÉ Même si le taux de suicide est faible dans les pays musulmans, des données indiquent que celui-ci est en hausse. Une analyse intégrée a été menée sur des données de tentatives de suicide (mortelles ou non) extraites d'études menées en République islamique d'Iran entre 1981 et 2007. Sur 54 études publiées sur le sujet, 48 d'entre elles, couvrant 26768 cas de tentatives de suicide, correspondaient aux critères d'inclusion. Le taux moyen pondéré de tentatives de suicide était de 26,5 pour 100000 et le taux moyen de décès par suicide était de 6,7 pour 100 000. L'âge moyen des personnes ayant fait une tentative de suicide était de 25 ans; $41,8 \%$ de ces personnes en moyenne étaient de sexe masculin ; 50,5\% étaient célibataires et 70,0 \% vivaient en milieu urbain. La majorité d'entre elles ne travaillaient pas : parmi elles, 54,2\% en moyenne étaient des femmes au foyer, $24,5 \%$ des étudiants et $21,0 \%$ des hommes sans emploi. Les dossiers médicaux ont permis de révéler que $16,2 \%$ des personnes ayant tenté de se suicider avaient des antécédents d'incapacité et 42,0\% des antécédents de troubles psychologiques. Les taux ont été comparés aux résultats d'études d'autres pays ou de différents groupes religieux.

${ }^{7}$ Social Determinants of Health Research Centre, Yasuj University of Medical Sciences, Yasuj, Islamic Republic of Iran. 


\section{Introduction}

Suicide is a growing problem worldwide [1,2]. According to World Health Organization estimates, approximately 850000 suicides leading to death occurred throughout the world in the year 2000 [3]. It has been estimated than in 2020 about 1530000 people will attempt suicide $[3,4]$. Although the rate of suicide is low in most Muslim countries $[3,5]$, there is evidence that it is increasing [6].

Suicide and attempted suicide have been occurring throughout human history and studies of suicide epidemiology have an important role in assessing the psychological health of a society [7]. According to a report by the American Psychiatric Society suicide is the second most common cause of death among students, the third cause of death of young people between the ages 15-24 years and the sixth cause of death of children below 15 years of age. Among these younger age groups of the population, suicide is the second cause of death after accidents [8-10]. Methods of attempting suicide vary across different countries, perhaps reflecting different lifestyles, cultures and religions [1]. The objective of this study was to integrate and analyse the data on suicide attempts from all studies carried out in the Islamic Republic of Iran from 1981 to 2007.

\section{Methods}

An integrated-analysis method was used. This technique combines information from various studies so that the number of people investigated increases and thus the power of the analysis and the precision of estimates will increase [11].

All published studies in English or Farsi languages concerning suicide attempts (nonfatal and fatal) in the Islamic Republic of Iran from 1981 to 2007 were considered. The main Internet search engines and resources used to find studies were: SID (the Iranian Scientific Information Database), IranMedex (index of articles published in Iranian biomedical journals), MagIran (the Scientific Magazines Bank of Iran), PubMed (database of United States National Library of Medicine) and databases of the World Health Organization Regional Office for the Eastern Mediterranean Region. The scientific research journals of the Iranian medical universities of were also searched. The research keywords used were suicide, self-burning, self-beating and poisoning.

The criterion for selection for this analysis was that the study had sufficient reliability in data collection methods and sources and methods of analysis. The scientific reliability of the articles was assessed by a third person who had good knowledge of the subject but was blind to the names of the authors and the journal. Out of 54 available studies, 48 were selected, which included data on 26768 cases of attempted suicide [12-59].

The data presented in these studies were extracted, recorded in a table which was prepared for this purpose and analysed using SPSS, version 17, and Excel, version 2003, software. The summary indices were calculated as weighted average of indices in each study based on the number of suicide attempt cases in each study using the fixed effects model.

\section{Results}

\section{Aggregated rates of suicide and suicide attempt}

As Table 1 shows, for the 7 studies in which data were available, the weighted mean rate of suicide attempts was 26.5 per 100000 population and the average rate of death by suicide was 6.7 per 100000.

\section{Demographic characteristics}

The demographic characteristics of the people attempting suicide are given in Table 2. Data on age, sex and marital status were available in 30 out of the 48 studies. The aggregated mean age (standard deviation) of suicide attempters was 25 (SD 3.6) years. The weighted mean proportion of males was $41.8 \%$. On average $50.5 \%$ of suicide attempters were single (never married).

Data on residence, employment, education and economic status were available in fewer studies (Table 2). On average, $70.0 \%$ of suicide attempts took place in an urban area. The rate of suicide attempts among those with educational level up to 12 years was $30.3 \%$ and this rate was higher than among those who had were illiterate (17.2\%) and or had 12 or more years of education (10.8\%). Most suicide attempters were not working: employment status showed that $54.0 \%$ were housewives, $24.5 \%$ were students and $21.5 \%$ were unemployed men. Economic status, reported in 12 studies, showed that suicide attempts were more common

\begin{tabular}{|c|c|c|c|c|c|c|}
\hline \multirow[t]{2}{*}{ Attempted suicide } & \multirow{2}{*}{$\begin{array}{c}\text { No. of studies } \\
\text { analysed }\end{array}$} & \multirow[t]{2}{*}{ No. of cases } & \multicolumn{4}{|c|}{ Rate per 100000 population } \\
\hline & & & $\begin{array}{l}\text { Weighted } \\
\text { mean (SD) }\end{array}$ & $95 \% \mathrm{Cl}$ & Min. & Max. \\
\hline Nonfatal & 7 & 6575 & $26.5(2.7)$ & $21.1-32.2$ & 0 & 35 \\
\hline Fatal & 7 & 6575 & $6.7(1.9)$ & $3.4-8.6$ & 1 & 12 \\
\hline
\end{tabular}

$S D=$ standard deviation; $C l=$ confidence interval . 


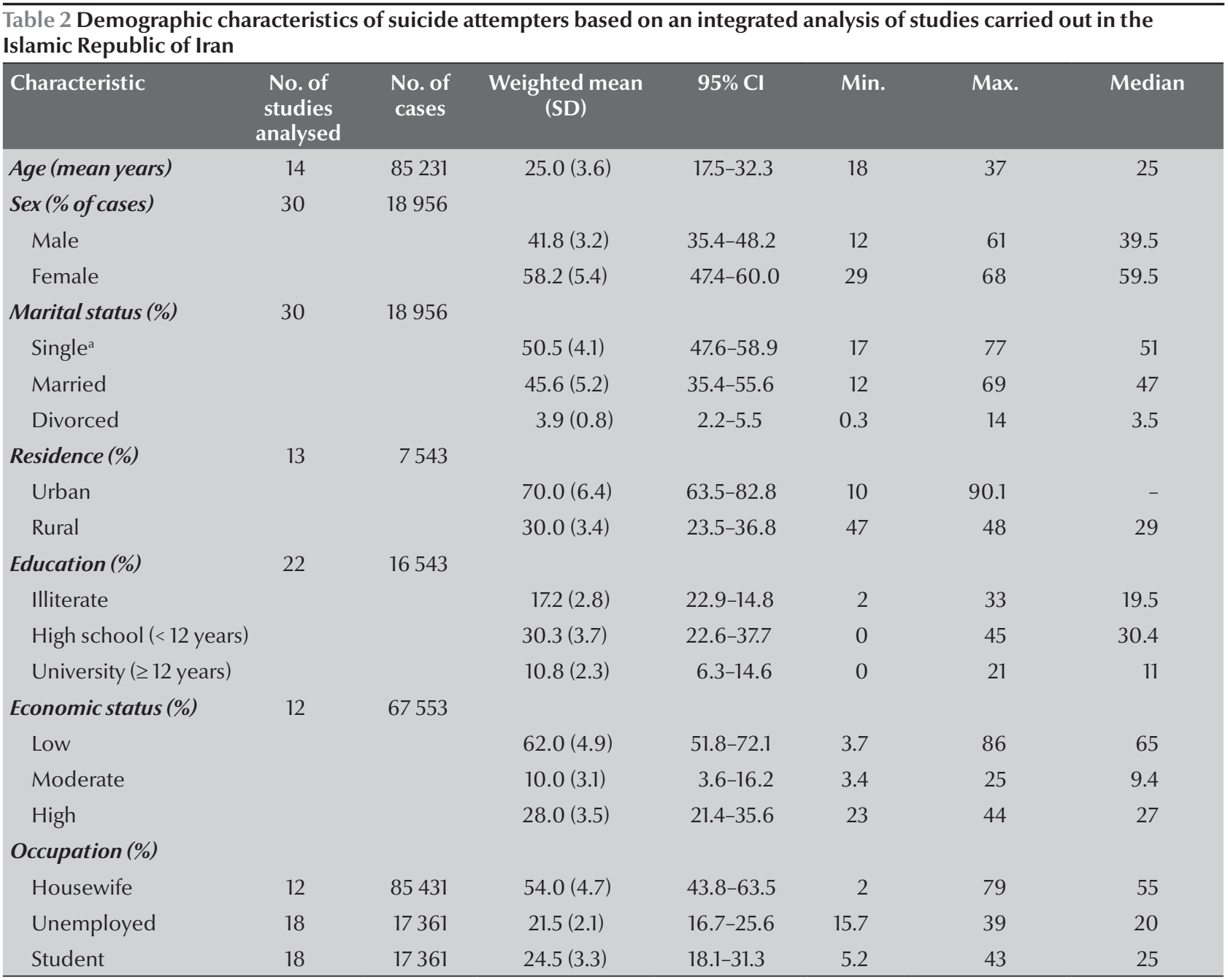

${ }^{a}$ Never married.

$S D=$ standard deviation $; C I=$ confidence interva $L$

in those with low income (62.0\%) than those with high $(28.0 \%)$ or moderate (10.0\%) levels of income.

\section{Medical history and reasons for suicide attempts}

Medical history, when available in the studies, showed that $16.2 \%$ of suicide attempters had a history of physical disorder and $42.0 \%$ had a history of mental disorder (32.6\% had a history of depression and $23.8 \%$ had a history of addiction) (Table 3 ).

On average, $24.8 \%$ of cases had made one or more previous suicide attempt. One-third of suicide attempters (32.0\%) had warned about their action beforehand. The most prevalent reasons for suicide attempt were family difficulties (49.5\%), emotional/relationship problems (17.5\%) and employment/ education problems (14.5\%).

The rate of suicide attempts was higher in summer (35.2\%) than other seasons.

\section{Suicide methods}

Drugs were the most common method of attempting suicide (65.0\%). Selfburning and poisoning were the second and third most common methods (15.0\% and $12.0 \%$ respectively) (Table 3). The rate of hanging was $9.1 \%$ and of suicide with firearms was $6.0 \%$.

\section{Discussion}

In this integrated analysis of 24256 attempted suicide cases in 48 studies the aggregated suicide rate in the Islamic Republic of Iran (6.7 per 100 000) was lower than in India (9.6 per 100000 ), Christian-majority countries (11.2 per 100000 ) and Buddhist countries (17.9 per 100000$)$ [1]. It was higher than in Muslim-majority countries (1 per 100 000) [1] but lower than Turkey (7.8 per 100000 ) [5]. The stigma of suicide in the religious context of Iranian society and the risk of subsequent legal problems for their family (e.g. burying the deceased) may mean that suicide is under-reported in the Islamic Republic of Iran.

The present analysis found that Iranian women attempted suicide 1.39 times more than men. This also agrees with studies in other countries; in European countries, for example, 


\begin{tabular}{|c|c|c|c|c|c|c|c|}
\hline \multirow[t]{2}{*}{ Variable } & \multirow{2}{*}{$\begin{array}{c}\text { No. of } \\
\text { studies } \\
\text { analysed }\end{array}$} & \multirow{2}{*}{$\begin{array}{c}\text { No. } \\
\text { of cases }\end{array}$} & \multicolumn{5}{|c|}{$\%$ of cases } \\
\hline & & & $\begin{array}{l}\text { Weighted } \\
\text { mean (SD) }\end{array}$ & $95 \% \mathrm{Cl}$ & Min. & Max. & Median \\
\hline \multicolumn{8}{|l|}{ Suicide history } \\
\hline $\begin{array}{l}\text { Warning before } \\
\text { attempting suicide }\end{array}$ & 10 & 5834 & $32.0(2.5)$ & 27.1-37.1 & 20.7 & 40 & 29.7 \\
\hline Previous suicide attempt & 17 & 19876 & $24.8(2.3)$ & 13.8-29.7 & 3 & 37 & 20 \\
\hline \multicolumn{8}{|l|}{ Method } \\
\hline Drugs & 21 & 15783 & $65.0(2.6)$ & $55.3-60.5$ & 41 & 88.5 & 67 \\
\hline Poisoning & 17 & 12346 & $12.0(3.1)$ & 5.1-18.8 & 6 & 30 & 13 \\
\hline Self-burning & 10 & 9783 & $15.0(4.6)$ & $6.2-24.3$ & 2.5 & 32 & 12 \\
\hline Hanging & 10 & 7673 & $9.1(2.3)$ & $4.7-13.4$ & 0.5 & 18 & 8 \\
\hline Gunshot & 6 & 4782 & $6.0(2.9)$ & $0.2-11.4$ & 0.5 & 10 & 10 \\
\hline Other & 4 & 2158 & $1.3(1.9$ & $0-4.5$ & - & - & - \\
\hline \multicolumn{8}{|l|}{ Reason } \\
\hline Family difficulties & 21 & 19431 & $49.5(2.8)$ & $43.2-45.4$ & 30 & 76 & 52 \\
\hline $\begin{array}{l}\text { Relationship/emotional } \\
\text { problems }\end{array}$ & 17 & 12371 & $17.5(2.1)$ & $12.2-21.7$ & 5 & 29.2 & 16.5 \\
\hline $\begin{array}{l}\text { Employment/education } \\
\text { problems }\end{array}$ & 17 & 16731 & $14.5(2.1)$ & 10.1-18.9 & 0.5 & 27 & 13 \\
\hline Other & 17 & 5423 & $2.1(18.5)$ & $14.1-22.9$ & - & - & - \\
\hline \multicolumn{8}{|l|}{ Medical history } \\
\hline Mental disorder & 22 & 21789 & $42.0(2.5)$ & $36.8-47.4$ & 9.6 & 52 & 39.6 \\
\hline Physical disorder & 22 & 19789 & $16.2(1.3)$ & 13.7-18.9 & 1 & 38 & 16 \\
\hline Substance dependence & 12 & 9187 & $23.8(2.4)$ & 19.0-29.6 & 7.2 & 35 & 23.2 \\
\hline Depression & 17 & 18731 & $32.6(3.4)$ & 28.3-39.4 & 9 & 47 & 27 \\
\hline Season & 10 & 8567 & & & & & \\
\hline Spring & & & $22.7(3.2)$ & 13.9-29.1 & 19.3 & 26 & - \\
\hline Summer & & & $35.2(2.0)$ & $31.2-40.4$ & 28.6 & 54 & - \\
\hline Autumn & & & $21.5(1.5)$ & $18.6-24.9$ & 20 & 33 & - \\
\hline Winter & & & $20.5(2.3)$ & $15.2-25.7$ & 19.1 & 24.7 & - \\
\hline
\end{tabular}

$S D=$ standard deviation $; C l=$ confidence interval .

women attempt suicide 1.5 times more than men [9]. In our analysis, there similar rates of suicide attempts among single and married people (50.5\% and 45.6\%), although other studies have found marriage to be a preventive factor in attempted suicide $[1-5,9,10,60]$. The most common age of suicide in Islamic Republic of Iran was among youth, as the average age was 25 years. This is similar to reports from most other countries $[1-11,60]$. Pritchard and Amanulah in an analysis of suicide in 17 predominantly Islamic countries contrasted with the UK concluded that suicide rates were higher for males than females, and older (65+ years) than younger (15-34 years) ages in every country reviewed [61]. The rate for males in the Middle East was 0-36 per million, South Asia 0-12 per million, Europe 53-177 per million and former USSR 30-506 per million, with 3 countries exceeding the UK rate of 116 per million. Suicide rates in Islamic varied widely and the authors concluded that the high rates of "other violent deaths" (ICD-9 category), especially in Middle Eastern countries, may be a repository for hiding culturally unacceptable suicides [61].
The rate of suicide attempts in this analysis was higher among those with high school education than those with no education and those with university level education. As for occupation, the highest rate of suicide attempts was among unemployed men and housewives. Of course, unemployment is linked to other social factors such as low literacy and financial problems. In New Zealand, unemployed men are 2 or 3 times at greater risk of attempting suicide than employed men $[1,4,60]$. Most suicide attempters in the Islamic Republic of Iran had low income, while in developed countries, suicide 
was more common in upper socioeconomic groups of society $[2,4]$. Qin et al. in a study of Denmark concluded that unemployment and low income had stronger effects on suicide in male subjects; living in an urban area was associated with higher suicide risk in female subjects and a lower risk in male subjects; and a family history of suicide raised suicide risk slightly more in female than in male subjects [62].

The most common reasons for attempting suicide were family difficulties, relationship/emotional and employment/education problems. This agrees with data from developing countries $[1,4,5]$. Considering the psychological and social stresses of youth and their perceived inability to solve their emotional problems and deal with life stressors, there is an important role for better life skills training and psychological support at home, school and university $[4,8]$.

The highest suicide rate in the Islamic Republic of Iran was in summer (35.2\%), nearly $13 \%$ higher than the other seasons, although these results do not agree with the findings from other countries [1]. A study in Finland found a strong seasonal effect on suicide occurrence, with the risk of suicide being greatest in spring [63]. The seasonal effect was most pronounced when the number of suicides was relatively low.

Suicide attempts in urban areas in the Islamic Republic of Iran were higher than in rural areas, which may be due to the greater stress imposed by urban lifestyles. This finding is similar to data reported from other countries $[1,8]$. More research is needed into reasons for higher rates of suicide in specific areas in order to plan interventions. For example, studies from Ilam province, near the border with Iraq, showed that it had the highest rate of suicide in Islamic Republic of Iran $[53,59]$ and suggests that this region needs more attention on suicide prevention than other regions of the country.

As reported elsewhere [4], drugs were the most common method of suicide attempts in the Islamic Republic of Iran, which may be due to the ease of use and accessibility of drugs. The second most common suicide method was self-burning. This method is rarely used in developed countries $[2,7,8,60]$. Cultural differences in attitudes to selfimmolation, storage of flammable fluids at home and the use of flammable materials such as kerosene for cooking may explain this difference.

About half of the people who attempted suicide had a history of mental disorders and approximately one-third of them had been diagnosed with depression. These results agree with studies in other countries $[1-10,60]$. Brent et al. in the United States found that the most significant psychiatric risk factors associated with adolescent suicide were major depression $(\mathrm{OR}=27.0)$, bipolar mixed state $(\mathrm{OR}=9.0)$, substance abuse $(\mathrm{OR}=8.5)$, and conduct disorder $(\mathrm{OR}=6.0)$ [64]. In our survey on average, about one-third of people who attempted suicide had a history of attempted suicide. Brent et al. also found that previous suicide attempts, suicidal ideation and homicidal ideation were associated with suicide among adolescents [64]. According to WHO, instigating mental health services after a person has attempted suicide is effective in reducing the risk of further attempts [3].

Suffering from a chronic physical disease will also increase the risk of suicide [9]. In our analysis, an average of $16.2 \%$ of people who attempted suicide had a history of physical disorders. In a study in Denmark $52 \%$ of suicide attempters interviewed were found to suffer from a somatic disease, and 21\% were on analgesics for pain [65]. Physicians need to be aware of the need not only for physical treatment but also for psychological support for patients with chronic diseases. This advice is reinforced by WHO [3] and is followed in many developed countries.

More targeted support, for example training about life skills, is needed for those at greater risk of suicide, especially young people, to help them to cope with family and emotional difficulties and employment and economic problems. Mental health services need to be aware of the higher risk of suicide among people with depression and those with previous suicide attempts but also people suffering from chronic physical health problems.

\section{Acknowledgements}

The present study was conducted with the support of the Social Determinants of Health Research Centre of Yasuj University of Medical Sciences. We thank the research committee of the University and all colleagues and students who helped us.

\section{References}

1. Bertolote MJ, Fleischmann A. A global perspective in the epidemiology of suicide. Suicidologi, 2002, 7, 2:6-8.

2. Suicide and deliberate self harm. In: Gelder $M$ et al., eds. Oxford textbook of psychiatry. Oxford, Oxford University Press, 1996, 4:14-17.

3. Suicide prevention (SUPRE). World Health Organization [online factsheet] (http://www.who.int/mental_health/prevention/suicide/suicideprevent/en/, accessed 28 February 2012).
4. Kerkhof ADJFM. Attempted suicide: pattern and trends. In: Hawton K, van Heeringen K, eds. Suicide and attempted suicide. New York, Wiley, 1998:49-64.

5. Sayil I, Devrimci-Ozguven H. Suicide and suicide attempts in Ankara in 1998: results of the WHO/EMRO Multicentre Study of Suicidal Behavior. Crisis, 2002, 23:6-11.

6. Pritchard C, Amanullah S. An analysis of suicide and undetermined deaths in 17 predominantly Islamic coun- 
tries contrasted with the UK. Psychological Medicine, 2007 37:421-430.

7. Lester D. Suicide and Islam. Archives of Suicide Research, 2006 , 10(1):77-97.

8. Knox K, Conwell Y, Caine E. If suicide is a public health problem, what are we doing to prevent it? American Journal of Public Health, 2004, 94, 1:37-45.

9. Gould M et al. Psychosocial risk factors of child and adolescent completed suicide. Archives of General Psychiatry, 1996, 53:1155-1162.

10. Phillips M, Zhang Y. Suicide rates in China, 1995-99. Lancet, 359:835-840.

11. Guan-Hua Huang. Integrated analysis of incidence, progression, regression and disappearance probabilities; Institute of Statistics, National Chiao Tung University, Hsinchu, Taiwan. BMC Medical Research Methodology, 2008, 8:40.

12. Solati K. [Survey of attitudes about suicide by self burning.] Journal of Shahrekord University of Medical Sciences, 2001, 2:52-60 [in Farsi].

13. Meamari A, Ramim T. [Factors in suicide of married woman.] Journal of Nursing and Midwifery Tehran University of Medical Sciences, 2005, 12(1):47-53 [in Farsi].

14. Ashkani H, Dehbozorgi GhR, Emamgholi PN. [Assessment of the epidemiological factors associated with suicide among the patients admitted in the psychiatric emergency ward.] Medical Journal of Tabriz University of Medical Sciences and Health Services, 2003, 56:21-16 [in Farsi].

15. Dibaei A, Ghareh Baghi R. [Study of suicidal burns in Ahwaz Forensic Medicine Center.] Journal of Legal Medicine of Islamic Republic of Iran, 2000, 19:10-15 [in Farsi].

16. Abasi A, Kamkar A. [Survey of relayed factors in suicide, Kohgyloieh and Boyerahmad province.] Armaghan-Danesh Journal of Yasuj University of Medical Sciences., 1994, 1:15-20 [in Farsi].

17. Shaikholeslami H, Flahzadeh M. [Suicides referrals to the emergency clinic of Qazvin.] Journal of Qazvin University of Medical Sciences and Health Services, 1997, 3:24-30 [in Farsi].

18. Esmaeil NT et al. [Causes of attempted suicide among women of Babol town, 2001-02.] Journal of Babol University of Medical Sciences, 2005, 26: 58-62 [in Farsi].

19. Tavallaii SA et al. [Risk factors correlated to suicide in deceased Iranian veterans.] Journal of Military Medicine, 2006, 2:143-148 [in Farsi].

20. Fathi AA, Eslami H. [Mental pathology and related factors in suicide attempt in soldiers.] Journal of Military Medicine, 2002, 4:249-245 [in Farsi].

21. Ashkani H, Moini SA, Tohidi M. [A study of suicidal attempts by drugs and poisonous substances in emergency rooms and intensive care units of hospitals affiliated with Shiraz University of Medical Sciences.] Journal of Medical Research of Shiraz University of Medical Sciences, 2002, 1:54-48 [in Farsi]

22. Yousefi M. [Evaluation of suicide with fire in Sanandaj.] Scientific Journal of Kurdestan University of Medical Sciences, 1997, 3:43-39 [in Farsi].

23. Ahmadi AR. [Frequency of self-immolation in the attempted suicide patients in Islam Abad Gharb, 1997-2003, Behbood.] Scientific Quarterly, 2005, 24:36-26 [in Farsi].

24. Khazaei H, Parvizi Fard AA. [Demographic characteristics and mental state evaluation of attempted suicide victims in Tabriz in 2001, Behbood.] Scientific Quarterly, 2003, 18:51-42 [in Farsi]

25. Khalkhali S, Rahbar M, Jamadi A. [Survey of life events prior to suicide attempt.] Journal of Guilan University of Medical Sciences, 2001, 10(39-40):96-106 [in Farsi].

26. Gh M, Saadaty A. [Survey of epidemiology and etiology of suicidal attempt and relation to socio demographic factors in the administrated emergency unit Central Hospital of Neishabur in 2003.] Quarterly Journal of Fundamentals of Mental Health, 2004, 23-24:117-125 [in Farsi].

27. Zarghami M, Khalilian AR. [Epidemiology of committing suicide in Kordkouy.] Pejohandeh Quarterly Research Journal, 2003, 35(8):370-361 [in Farsi].

28. Yasami MT, et al. [Epidemiological survey of suicide through the forensic medical center in the province of Kerman.] Quarterly Journal of Andeesheh Va Raftar, 2002, 28:12-14 [in Farsi].

29. Bolhari J et al. [The prevalence of suicide attempt in proportion of referrals to emergency departments in Karaj.] Hakim Research Journal, 2007, 1:50-55 [in Farsi].

30. Nojomi $\mathrm{M}$ et al. [Predicting factors of suicide attempts in Karaj general population.] Quarterly Journal of Andeesheh Va Raftar, 2007, 3:219-226 [in Farsi].

31. Taziki $M$ et al. [Epidemiological survey of suicide in Golestan province in the North of Iran (2003).] Journal of Mazandaran University ofMedical Sciences, 2006, 55:72-77 [in Farsi].

32. Rahbar $M$ et al. [Survey of suicidal epidemiologic factors in emergency ward patients of Razi Hospital, Rasht.] Journal of Legal Medicine of Islamic Republic of Iran, 2004, 34:95-91 [in Farsi].

33. Mousavi F, Shah Mohammadi D, Kaffashi A. [Epidemiological survey of suicide in rural areas.] Quarterly Journal of Andeesheh Va Raftar, 2000, 20:10-14 [in Farsi].

34. Malek A, Poor Afkari N, Dastgiri S. [A study on deliberate selfpoisoning in Tabriz, Iran.] Medical Journal of Tabriz University ofMedical Sciences and Health Services, 1997, 33(31):103-114 [in Farsi].

35. Pourmand D, Davidian L. [Attempted suicide in patients with psychiatric disorders.] Journal of Medical Council of Islamic Republic of Iran, 1996, 14(1-2):15-21 [in Farsi].

36. Mehran $\mathrm{N}$ et al. [Social and psychological characteristics of suicide attempters in comparison with normal individuals in Birjand.] Journal of Birjand University of Medical Sciences, 2004, 20:28-22 [in Farsi].

37. Zarghami M, Khalilian A. [Psychiatric and physical disorders in suicide attempted by self-burning.] Hakim Research Journal, 2003, 4:270-263 [in Farsi].

38. Ahmadi AM, Haji Ahmadi M. [An epidemiological report on successful suicide in Mazandaran province in 1990-91.] Journal of Mazandaran University of Medical Sciences, 2000, 28:12-18 [in Farsi].

39. Saberi M, Ghorbani R, Mousavi Sh. [Epidemiologic study on suicide attempt in affiliated hospitals of Semnan University of Medical Sciences, Koomesh.] Journal of Semnan University of Medical Sciences, 2005, 4:317-311 [in Farsi].

40. Yousefi H, Sobhani Gh, Asadinoghabi F. [Suicide risk factors between those who committed suicide, Bandar Abbas, Iran.] Medical Journal of Hormozgan University, 2002, 6(2):13-20 [in Farsi].

41. Memari A et al. [Causes of suicide in married women.] Journal of Faculty of Nursing and Midwifery, 2006, 1:47-53 [in Farsi].

42. Ahmadi A et al. [Epidemiological study of committed selfinflicted burns admitted to the Hospitals of Kermanshah, University of Medical Sciences, Iran.] Quarterly Journal of Fundamentals of Mental Health, 2006, 29/30:23-35 [in Farsi].

43. Kaviani H, Rahimi P, Naghavi H. [Iranian depressed patients attempting suicide showed impaired memory and problemsolving.] Archives of Iranian Medicine, 2004, 7:113 [in Farsi].

44. Khalkhali $\mathrm{S}$ et al. [Contact with physicians prior to suicide attempt.] Hakim Research Journal, 2007, 4:17-23 [in Farsi].

45. Mohammadi N, Karbakhsh M, Pajoumand A. [Epidemiologic aspects of deliberate self-poisoning in adolescents: a hospital- 
based study in Tehran.] Tehran University Medical Journal, 2007, 4(65):59-64 [in Farsi].

46. Ziaee A. [A critical appraisal of assessment and critics of systematic review and meta analysis.] Journal of Urology of Iran, 2001, 8:34-41 [in Farsi].

47. Zohoor AR, Aflatoonian MR.[ Epidemiological study of attempted suicide in Jiroft, Kerman (autumn 2001).] Journal of Iran University of Medical Sciences, 2004, 38:920-913 [in Farsi].

48. Amirmoradi $\mathrm{F}$ et al. [Investigating causes of self-burning in married women.] Journal of Faculty of Nursing and Midwifery, 2005, 24/25:41-50 [in Farsi].

49. Moradi S, Khademi A. [Evaluation of suicides resulting in death in Iran, comparing with the world rates.] Journal of Legal Medicine of Islamic Republic of Iran, 2002, 27:21-16 [in Farsi].

50. Hossein Pour M, Ghaffari SM, Mehrabi Zadeh M. [A study on the incentives of suicide attempts among adolescents referred to Golestan Hospital of Ahwaz in 1379-80.] Scientific Medical Journal of Ahwaz University of Medical Sciences, 2004, 4(1):24-30 [in Farsi].

51. Ghaedi $\mathrm{H}$ et al. [Epidemiological study of suicide attempt in Dashtestan region in 2004, Dena.] Quarterly Journal of Yasuj Faculty of Nursing and Midwifery, 2007, 3:53-60 [in Farsi].

52. Mehdi Zadeh M, Zamani GhR, Kabiri M. [Attempt to suicide in children in Loghman hospital.] Indian Journal of Pediatrics, 2006, 3:342-337 [in Farsi].

53. Rezaeian $\mathrm{M}$ et al. [Suicide by self burning.] Rafsanjan University of Medical Sciences, 2006, 6(5):16-22 [in Farsi].

54. Mousavi $\mathrm{F}$ et al. [Family factors associated with suicide attempts.] Social Welfare, 2006, 7:53-72 [in Farsi].

55. Shirzad J, Gharebaghee J. [Evaluation methods and causes of suicide lead to death, referred to the Legal Medicine Organization in the first six months of 2003.] Journal of Legal Medicine, 2005, 13(47):163-170 [in Farsi].
56. Barkhordar N, Jahangir K, Barkhordar N. [Survey of suicide trend and its risk factors in rural areas of the city of Kermanshah (during the years 2000 to 2004).] Journal of Medical Council Islamic Republic of Iran, 2007, 27(2):219-225 [in Farsi].

57. Safa M et al. [Characteristics of personal, familial, psychological and substance abuse in patients admitted to hospital on suicide attempt.] Journal of Lorestan University of Medical Sciences, 2006, 9(2):31-37 [in Farsi].

58. Sqhtoleslam T, Rezaei O, ShahBeigi S. [Suicide in Iranian children.] Journal of Neurosciences, 2005, 5(15-16):1-9 [in Farsi].

59. Jonghorbani $M$, Sharifirad G. Completed and attempted suicide in Ilam, Iran (1995-2002): incidence and associated factors. Archives of Iranian Medicine, 2005, 8:119-126.

60. Moscicki E. Epidemiology of suicide. International Psychogeriatrics, 1995, 7:137-148.

61. Pritchard C, Amanulah S. An analysis of suicide and undetermined deaths in 17 predominantly Islamic countries contrasted with the UK. Psychological Medicine, 2007, 37(3):421-430.

62. Qin P, Agerbo E, Mortensen PB. Suicide risk in relation to socioeconomic, demographic, psychiatric, and familial factors: a national register-based study of all suicides in Denmark, 1981-1997. American Journal of Psychiatry, 2003, 160:765-772.

63. Partonen $\mathrm{T}$, Nevanlinna $\mathrm{H}$, Lönnqvist J. Analysis of the sean sonal pattern in suicide. Journal of Affective Disorders, 2004, 81(2):133-139.

64. Brent DA et al. Psychiatric risk factors for adolescent suicide: a case-control study. Journal of the American Academy of Child and Adolescent Psychiatry, 1993, 32(3):521-529.

65. Stenager EN, Stenager E, Jensen K. Attempted suicide, depression and physical diseases: a 1-year follow-up study. Psychotherapy and Psychosomatics, 1994, 61:65-73. 